\title{
Brasil em tempo de cinema como método de análise fílmica de Jean-Claude Bernardet ${ }^{1}$
}

\section{Margarida Maria Adamatti}

\section{Resumo}

Escrito no auge do fenômeno do Cinema Novo, Brasil em tempo de cinema (1967), de Jean-Claude Bernardet, foi a primeira obra analítica sobre 0 movimento. Pioneiro na crítica à cultura do nacionalpopular, o livro tornou-se peça obrigatória para 0 debate dos realizadores e uma referência teórica sobre 0 cinema brasileiro para os críticos. 0 artigo avalia 0 método de análise fílmica desenvolvido por Bernardet a partir do diálogo com a sociologia das visões de mundo e com a crítica materialista para traçar um panorama da evolução desses conceitos na crítica dos anos 1970.

\section{Palavras-Chave}

Brasil em tempo de cinema. Jean-Claude Bernardet. Cinema Novo. Cultura do nacional-popular. Lucien Goldman.
Margarida Maria Adamatti I mmadamatti@hotmail.com Doutora em Meios e Processos Audiovisuais pela Universidade de São Paulo - USP, Brasil. Desenvolve pesquisa de pós-doutoramento no Programa de Pós-Graduação em Imagem e Som da Universidade Federal de São Carlos - UFSCar, Brasil.

\section{Introdução}

Durante o Festival É tudo verdade de 2006, em uma homenagem a Jean-Claude Bernardet, 0 cineasta Eduardo Coutinho contou que Cabra marcado para morrer (1984) foi feito em parte como "resposta às questões que o Jean-Claude colocava" (BERNARDET, 2007: p. 11). Coutinho tinha lido Brasil em tempo de cinema (1967) e se sentia provocado o tempo todo pelos textos de Bernardet. Ele não foi o único realizador a admitir isso. Em conversa reservada, Arnaldo Jabor contou a Bernardet que o crítico havia notado aspectos de Opinião Pública (1966) despercebidos pelo próprio diretor.

Brasil em tempo de cinema marcou o debate cinematográfico como a primeira obra de peso sobre o Cinema Novo. Em entrevista, Sérgio Augusto e José Carlos Avellar comentaram 0 quanto o livro foi importante para uma geração de críticos². 0 escritor José Arrabal, famoso por inaugurar a crítica à cultura do nacional-popular na crítica teatral dos anos 1970, teve em Brasil em tempo de cinema sua inspiração enquanto 
método de análise. Para o jornalista e crítico de cinema Clóvis Marques, a publicação foi uma peça fundamental em sua trajetória: "Li esse livro nessa época. 0 Bernardet era a leitura importante da época. Foi assim uma espécie de um clarão para a crítica de cinema brasileira nessa época; é como se com o Bernardet, ela tivesse alcançado uma maioridade intelectual e política que não tinha ainda".

Declarações como esta dão uma pequena dimensão de como Brasil em tempo de cinema tornou-se um parâmetro para 0 exercício da crítica de cinema dos anos 1970. A proposta deste artigo é avaliar o método de estudo de Bernardet ao cinema brasileiro. A partir da interação com a sociologia das visões de mundo, com a crítica materialista e com a análise imanente, interessa-nos demonstrar como a rearticulação em torno de referências teóricas daquele momento serviu de inspiração para o exame da filmografia nacional. Procuramos revelar as reapropriações de conceitos, visando a uma compreensão mais ampla do percurso de Jean-Claude Bernardet. Não se trata de uma comparação com fins valorativos, nem de pensar a crítica de cinema como procedimento único de um teórico. Afinal, os parâmetros analíticos dos articulistas cinematográficos eram criados no diálogo com o contexto político, com a cultura do nacional-popular e com a discussão em torno do conceito de autoria.

Nos anos 1960 e 1970, o acesso à moviola era muito raro entre os críticos de cinema. A solução adotada era contar com a memória ou fazer anotações manuscritas no escuro durante a projeção. Em geral, os articulistas conseguiam ver um filme, no máximo, duas vezes antes de escrever. Jean-Claude Bernardet redigiu Brasil em tempo de cinema nesse contexto, e, por causa dessa falta de acesso irrestrito aos materiais, ele fez uma severa autocrítica após sua publicação. Para 0 autor, 0 escasso contato com as obras gerava pesquisas superficiais que prejudicavam o estudo interno dos filmes. Se a declaração remonta às condições de trabalho da crítica, é inverdade afirmar que Bernardet não estava atento à descrição detalhada dos planos e ao específico do cinema. Nesse fator reside, de fato, uma das grandes virtudes do livro. Por exemplo, as análises imanentes detalhadas de Bernardet dos filmes Porto das caixas (1962) e $O$ desafio (1964), ambos de Paulo César Saraceni, São Paulo Sociedade Anônima (1965), de Luiz Sérgio Person, Barravento (1961), de Glauber Rocha, etc., foram incorporadas à maneira de uma estrutura significativa pelas pesquisas ao longo das décadas.

Parte desse trabalho foi apresentado no XX Encontro Socine, em outubro de 2016.

As entrevistas de Sérgio Augusto, José Carlos Avellar, José Arrabal, Clóvis Marques e Jean-Claude Bernardet foram concedidas a ADAMATTI (2015). 
Com a invasão da Universidade de Brasília pelos militares em 1965, Jean-Claude Bernardet foi impedido de defender sua dissertação de mestrado. Com um título tomado de empréstimo de Cacá Diegues, Brasil em tempo de cinema só foi lançado em 1967. 0 objetivo era debater a produção brasileira realizada entre 1958-1966 sem adotar um critério cronológico ou artístico. Em pouco tempo, o livro transformou-se na principal obra sobre 0 Cinema Novo, alçando Bernardet à categoria do mais importante teórico do movimento.

Sem separar a produção entre cinema artístico, de gênero ou comercial, Brasil em tempo de cinema examina a filmografia brasileira como um todo orgânico e como resultado de um trabalho coletivo. Em conjunção à voga do estruturalismo e da linguística, não se frisa a trajetória individual ou autoral do cineasta, mas o conjunto de filmes como estatuto socialmente construído (Stam, 2003). Como método de trabalho, Bernardet utilizava formas de análise da literatura e da composição dos personagens para estabelecer comparações com a estrutura fílmica. Havia uma vontade de intervir no debate, que tem relação direta com o ambiente cultural daqueles anos. Após a eclosão do Cinema Novo, críticos como Bernardet e Gustavo Dahl afastaram-se da discussão centrada na autoria e deram preferência aos filmes que abriam um diálogo com a realidade brasileira. Esse desejo de intervir na sociedade através da ação dos textos trouxe uma metodologia para a crítica de cinema, unificando critérios estéticos e políticos.
A primeira repercussão do livro no meio cinematográfico não foi positiva. Para compensar a ausência da banca de mestrado, Pompeu de Souza convidou Bernardet para defender a dissertação publicamente durante a Semana do Cinema Brasileiro, organizada por Paulo Emilio Salles Gomes. "Um dos debatedores foi Paulo César Saraceni que, segundo Bernardet, ficou bastante irritado com a tese. Falou de sua irritação, mas sem agressividade" (Pereira, 2001: p. 80). A polêmica surgiu porque o livro traçava um paralelo entre os cineastas e sua classe social e ainda questionava a noção de cinema popular do Cinema Novo. Na época, muitos realizadores cinemanovistas viam-se como sujeitos responsáveis por fazer aflorar a cultura popular e emancipar criticamente o público. Observando a inexistência no Brasil de um cinema popular, Bernardet contestava o papel dos realizadores como representantes autênticos dessa cultura. Com essas afirmações, ele levava embora 0 sonho cinemanovista de ser um mediador autorizado do povo.

0s comentários eram uma clara crítica à cultura engajada predominante na esquerda. Em entrevista, Ismail Xavier (2009) comentou que Brasil em tempo de cinema foi pioneiro na crítica à cultura do nacional-popular. Se essa cultura política ruiu totalmente entre os intelectuais de esquerda no final dos anos 1970 e início de 1980 (Napolitano, 2011), demonstramos neste artigo como Bernardet foi um dos pioneiros desse questionamento ainda em 1965, lado a lado com 0 
texto de Sebastião Uchôa Leite (1965), publicado na Revista Civilização Brasileira.

Se Ismail Xavier frisou o caráter pioneiro de Brasil em tempo de cinema, ele apontou como o livro adotou uma correspondência nem sempre consistente entre 0 personagem e a classe social. Por causa disso, a noção de classe média surgia como um determinante da produção do Cinema Novo. Se os cineastas não gostaram de ser chamados de intermediários não autorizados do popular, o ponto mais polêmico era, sem dúvida, a pecha de pertencer à classe média. 0 referencial está longe da Política dos Autores e da ideia de prolongamento entre o personagem e 0 diretor enquanto visão de mundo individual. 0 livro adota a perspectiva do prolongamento entre personagem e cineasta, mas como visão de mundo de uma classe social. Afinal, a inspiração advém da crítica materialista e da sociologia das visões de mundo.

\section{A estrutura cinematográfica brasileira e 0 diálogo com a sociologia das visões de mundo}

0 paralelo entre a estrutura fílmica e a social de Brasil em tempo de cinema toma inspiração na sociologia das visões de mundo de Lucien Goldman, cujo método dialético desloca-se entre 0 texto, a visão de mundo e a história. 0 foco recai no modo com 0 qual as estruturas mentais são produzidas historicamente. Interessava a Goldman decompor a visão de mundo de uma classe social através de uma ação conjunta, da qual fazem parte o comportamento político, os conceitos filosóficos e, especialmente, a imaginação criadora. 0 sociólogo queria demonstrar como a situação histórica de um grupo é transposta por meio da mediação de sua visão de mundo para a estrutura da obra literária (LÖWY; NAÏR, 2008). Goldman não frisa o conteúdo ou a biografia de um artista, mas a estrutura da obra, tanto na sua forma quanto no contexto, com o objetivo de examinar em que grau um texto incorpora a visão de mundo de uma classe social.

A estrutura mental de um conjunto social não é estática para Goldman. Ao contrário, ela é o resultado da ação de um grupo dentro de um processo ininterrupto de acomodações e assimilações de novas formas de percepção. A inspiração vem da teoria de Jean Piaget e da certeza de que o homem modifica ininterruptamente a realidade em um processo contínuo de construção de estruturas mentais por meio da interação com o grupo (FREDERICO, 2005). Dessa forma, novas estruturas de pensamento são criadas de maneira inconsciente pela desestruturação das antigas categorias:

\footnotetext{
"A relação essencial entre a vida social e a criação literária não diz respeito ao conteúdo da realidade humana, mas somente às estruturas mentais, que se podem chamar de categorias que organizam por sua vez a consciência empírica de certo grupo social e de um universo imaginário criado pelos escritores. [...] Pode-se dizer que as estruturas mentais, ou para empregar um termo mais abstrato, as estruturas categóricas significativas, não são mais que fe-
} 
nômenos individuais, mas fenômenos sociais." GOLDMAN (1967: p. 532-534)3.

A chamada estrutura categórica significativa, isto é, a estrutura mental de uma classe social, envolve a forma, o conteúdo e o pensamento dos autores. 0 processo resulta em um complexo esforço social que garante um caráter coletivo para a criação artística. Como consequência, Goldman observa que existe uma homologia entre a estrutura da obra e a estrutura mental de certos grupos sociais:

"A relação já mencionada entre a estrutura da consciência de um grupo social e a de seu universo constitui, nesse caso a mais favorável para o pesquisador, uma homologia mais ou menos rigorosa, mas frequentemente também uma simples relação significativa. Se pode então chegar, nessa perspectiva - e isso acontece mesmo com mais frequência - que os conteúdos inteiramente heterogêneos e mesmo opostos sejam estruturalmente homólogos" (GOLDMAN, 1967: p. 533) ${ }^{4}$.

Bernardet aplica o conceito goldmaniano de homologia das estruturas significativas para analisar a produção brasileira, com especial interesse pelo Cinema Novo. Ele inicia o percurso pelo conteúdo das obras e pela composição dos personagens para refletir sobre uma equivalência entre a realidade social e a criação artística conjunta. Sem procurar semelhanças de estilo entre dois realizadores, Bernardet olha para conteúdos heterogêneos de cineastas com concepções estéticas opostas, mas, mesmo assim, encontra uma homologia estrutural. Assim, ele localiza uma estrutura comum entre filmes totalmente diferentes do ponto de vista formal e ideológico como Noite vazia (1964), de Walter Hugo Khouri, e Deus e o diabo na terra do sol (1964), de Glauber Rocha. A partir dessa constatação, o autor abre um paralelo com certa postura política dos cineastas em nível inconsciente:

\begin{abstract}
"Se, por volta de 1960, as obras resultam frequentemente de um projeto político consciente, nem sempre lúcido, e os cineastas colocam todas as suas intenções no nível do conteúdo, aos poucos, por um processo de sedimentação, grande parte do significado deixou de ser tão consciente e passou para a estrutura" (BERNARDET, 2007: p. 171).
\end{abstract}

0 autor observa que existe uma estrutura inconsciente que incide em cineastas brasileiros com estilos muito diferentes. Em comum, haveria uma tendência à polarização dos personagens.

Em Deus e o diabo na terra do sol, Bernardet vê uma estrutura simétrica, representada de maneira maniqueísta nas duas faces da revolta de Manuel, nos polos de Deus e do Diabo, entre o bem e 0 mal ou entre 0 beato e 0 cangaceiro. Em Noite vazia, existiria uma simetria entre os casais: o pervertido e o romântico puro, o sonho calmo 
e a solidão angustiada. Se os dois casos trazem simetrias, a maior ambiguidade de polarização ocorreria em Bahia de todos os santos (1961), de Trigueirinho Neto. 0 personagem Tonio reúne várias contradições sociais dentro de si. Não é branco, nem negro, mas dessa indefinição acaba rejeitado pelos dois grupos étnicos. Ele tem um relacionamento com uma estrangeira, mas a personagem é dominadora e preconceituosa. Seu sonho é partir para o sul do país, contudo, lhe falta coragem. Por causa dessa postura pendular, Tonio incorpora uma sensação constante de desejar algo e repelir ao mesmo tempo. Para analisá-lo, Bernardet toma o conceito de prolongamento entre o personagem e 0 diretor, mas não procura por uma expressão pessoal da autoria. 0 paralelo serve, na verdade, para observar uma postura flutuante e indecisa igualmente entre Tonio e 0 cineasta Trigueirinho Neto.

A observação descrita anteriormente sobre a crescente polarização dos filmes brasileiros poderia ser pensada como uma simples tendência ao maniqueísmo, mas Bernardet preferiu correlacionar o comportamento dos personagens com a classe social e a visão de mundo dos cineastas. Por causa disso, o cinema nacional é visto como o resultado de um trabalho coletivo dos realizadores:

"É válido perguntar se essa situação entre dois polos, fundamental para numerosas personagens e para 0 conjunto da temática do cinema brasileiro, não poderia atingir, não apenas personagens, mas também a própria estrutura dos filmes" (Bernardet, 2007: p. 128).
"A gestação de Antonio das Mortes, 0 aparecimento de Carlos e Marcelo, a lenta elaboração de enredos e personagens cujas estruturas possam ter um valor equivalente a certas estruturas da sociedade brasileira são a elaboração não apenas de uma temática, mas também de uma forma que expresse a problemática brasileira" (BERNARDET, 2007: p. 164).

A proposta do livro é avaliar se a polarização dos personagens reflete uma estrutura conjunta do cinema brasileiro e da realidade do país. Busca-se analisar a conversão em imagens do pensamento conjunto dos cineastas. Para chegar a essa conclusão, Bernardet traça um paralelo entre o comportamento político de uma determinada classe social e a representação que ela faz de si mesma nos filmes. Pelos exemplos colhidos, o autor demonstra a quase ausência da representação de personagens da classe média nas obras, que é o estrato social mais comum de origem dos realizadores brasileiros.

Se nos filmes a classe média está ausente, ou é oscilante e ambígua, Bernardet dedica-se a entender as razões desta operação. Com esse percurso enunciativo, ele compara a estrutura das obras com a estrutura do pensamento político dos cineastas. Porque não possui um projeto político e econômico claro, a classe média hesita entre a burguesia e o povo. Como consequência, ela tenta assimilar valores populares e evita representar-se nos filmes. Dessa hesitação, surge uma estrutura simétrica em pares dicotômicos, isto é, personagens maniqueístas e, no fundo, incapazes de endossar um projeto político. A 
tendência à polarização só teria sido rompida com o golpe militar, quando a classe média surgiu na tela com grande apatia, marasmo e perplexidade, por exemplo, em $O$ desafio (1964), de Paulo César Saraceni, e São Paulo Sociedade Anônima (1965), de Luís Sérgio Person.

Sem contar com um estudo anterior sobre a intelectualidade ou a classe média daquele período, Bernardet adotou a sociologia das visões de mundo para destrinchar o paralelo entre 0 comportamento político dos cineastas, sua visão de mundo e os personagens da tela. A intenção do livro não era somente decompor a representação de determinado grupo social no cinema, mas também avaliar o projeto político da classe média. Se Brasil em tempo de cinema queria intervir no debate, os próprios cineastas surgiam como receptores em potencial. Bernardet procurava dialogar com os realizadores citados para revelar como, inconscientemente, eles reproduziam parte da estrutura significativa da classe média.

Ele demonstrava que os cineastas nem sempre tinham consciência da "visão ideológica objetiva" dos filmes. Se os significados, às vezes, são involuntários e contradizem intenções, o objetivo do livro era fazer 0 cineasta adquirir ciência dessas estruturas sedimentadas e conservadoras de pensamento.

Por exemplo, para revelar a "ideologia objetiva", Bernardet demonstra quais são os filmes de esquerda dotados de um pensamento de direita. Eis que, novamente, surge Bahia de todos os santos (1961) como exemplo da presença das contradições de Trigueirinho Neto. 0 critério utilizado é o processo de identificação entre cineasta, personagem e público. Na história, Tonio vive de pequenos furtos e ajuda na fuga de um grevista. Por causa disso, ele é enviado a um reformatório. Bernardet chama a atenção para a cena final, quando Tonio aconselha 0 amigo a não roubar, incorporando regras sociais criticadas antes:

"[...] Trigueirinho Neto não levou às últimas consequências as contradições de sua personagem. [...] Trigueirinho Neto tem uma raiva profunda e dolorosa, mal tingida de ironia, da burguesia [...]. Trigueirinho Neto quer que a sociedade mude, pois é insustentável que fique como está, mas seu antiburguesismo primário não leva a coisa alguma a não ser reforçar a moral burguesa" (BERNARDET, 2007: p. 90).

0 estudo anterior se baseia na comparação entre o posicionamento do personagem e a visão de mundo expressa pelo diretor. Se na cena final Tonio prefere uma espécie de compromisso moral, Brasil em tempo de cinema vê em Trigueirinho Neto um reforço dos valores burgueses e uma fuga inconsciente de sentido político. Quando Bernardet traça um paralelo com a classe social do cineasta, como já vimos, há também um diálogo profícuo com outro teórico do período.

\section{A associação com Roland Barthes}

0 trecho anterior interage de perto com um conceito do livro Mitologias, de Roland Barthes, publicado pela primeira vez em 1957: 
"Existem, sem dúvida, certas revoltas contra a ideologia burguesa. [...] Mas tais revoltas são socialmente limitadas e permanecem recuperáveis. [...] E, ademais, estas revoltas se inspiram sempre numa distinção muito nítida entre 0 burguês ético e 0 burguês político; 0 que a vanguarda contesta é o burguesismo da arte e da moral; [...], mas contestação política, nenhuma" (BARTHES, 2003: p. 231).

A matriz de pensamento para analisar Trigueirinho Neto está nesse trecho de Barthes. Depois de assistir a um espetáculo de luxo e sonho, o público conclui que a riqueza não compensa exatamente pelo cunho moral. Dessa forma, a condenação ao sistema torna-se apenas um critério ético, sem nenhum tipo de contestação política, tal como foi feito por Bahia de todos os santos.

Encontramos em Roland Barthes (2003: p. 243-4) a fonte para outro conceito fundamental de Brasil em tempo de cinema: o processo de identificação e sua função na emancipação crítica do público. 0 comportamento da burguesia, descrito em Mitologias, serve de espelho para a classe média brasileira. De acordo com o semiólogo francês, a burguesia "degradada" não consegue verse refletida na tela porque os personagens são falsos. Graças aos papéis estereotipados e artificiais, o processo de identificação permanece em suspenso, e o espectador é impedido de imaginar o outro ou de se ver na tela. 0 mecanismo impede a análise do grupo. Assim, o espectador aplaude a produção, paga 0 ingresso e não macula sua consciência. 0 que está implícito nessa linha de raciocínio é predeterminar a fruição, como se fosse fundamental 0 espectador passar pela identificação autocrítica para tomar consciência da realidade.

Bernardet tomou os comentários sobre 0 mecanismo de identificação para repensar a adaptação cinematográfica da obra de Nelson Rodrigues. Novamente, a base do pensamento é 0 prolongamento entre os personagens e 0 diretor. A finalidade é demonstrar que Nelson Rodrigues não fez um teatro desagradável, como o dramaturgo diz. Ao contrário, o público de classe média sente-se recompensado ao observar que a riqueza não vale a pena do ponto de vista moral, porque os ricos são corruptos, perdidos e angustiados. Por causa de tudo isso, as peças são incapazes de alterar o status quo. Como consequência, o espectador não percebe sua situação e culpa. Desse modo, tanto 0 teatro desagradável de Nelson Rodrigues quanto o sentimento de revolta de Trigueirinho Neto contra sua própria classe perdem eficácia junto ao receptor. Isso ocorre porque o público jamais irá conseguir ver-se retratado na tela. Dessa maneira, o mecanismo garante que 0 processo de identificação permaneça suspenso. Portanto, mesmo com toda a agressão à burguesia nos filmes, o resultado é conformista, porque não se atinge 0 sentimento do espectador. Nesse sentido, Nelson Rodrigues é visto somente como reflexo de sua classe social, assim como Trigueirinho Neto. 
Os trechos citados anteriormente apontam como o diálogo com Goldman e Barthes esteve presente na composição do método de análise do cinema brasileiro de Jean-Claude Bernardet. A conexão entre os autores expõe o quanto a metodologia da crítica de cinema dos anos 1960 não utilizava somente os critérios artísticos, mas também incorporava os olhares do campo da sociologia e da crítica voltada a desmistificar a cultura de massa, como um diferencial analítico.

Mesmo assim, após a publicação do livro, Jean-Claude Bernardet fez uma autocrítica severa que se mantém até a atualidade ${ }^{5}$. Para 0 autor, Brasil em tempo de cinema serviria para avaliar um romance, porém haveria uma insuficiente aproximação em relação às formas e à materialidade do cinema. Ela seria causada por uma perspectiva sociológica superficial, cuja consequência é traçar relações mecânicas entre o cunho dramático e a classe social. Fato é que, sem uma literatura sobre a classe média ou sobre a intelectualidade brasileira, Bernardet desenvolveu o primeiro estudo de peso sobre o Cinema Novo. Depois disso, ele empenhouse em buscar a materialidade cinematográfica através do acesso aos filmes na moviola, utilizando o laboratório de Thomas Farkas. Essa preocupação o levou depois a procurar na semiologia acesso às formas fílmicas. Assim, Bernardet foi estudar com Christian Metz, traduziu para o português $A$ significação no cinema (Metz, 1972) e escreveu o posfácio do livro, abordando São Paulo S.A (1965), de Luís Sérgio Person, sob o prisma da semiologia.

Contudo, é enganoso pensar que Brasil em tempo de cinema não se dedique à materialidade do cinema. Se a correlação entre a classe social e a visão de mundo traçada no livro foi considerada datada, há um olhar extremamente acurado, diversas descrições de planos e observações pertinentes feitas de memória. Esse trajeto de pesquisa vai na contramão da tendência de estudar o cinema enquanto produção autoral. Em um período de crescente interesse pelo estruturalismo, Bernardet não deixava de lado o específico cinematográfico, mas utilizava outras ferramentas de trabalho. 0 interesse recaía sobre uma produção com estética apurada, responsabilidade diante da realidade e expressão da sensibilidade pessoal. Dessa conjunção de fatores, Bernardet congregava valores advindos do campo da estética e da política à análise fílmica.

Em alguns momentos, 0 livro vê o perfil do personagem como um prolongamento determinante do diretor. Por outro lado, seria errado afiançar a existência apenas desse viés, porque, muitas vezes, Brasil em tempo de cinema incorpora a análise imanente como forma de abordar a relação entre 0 discurso dos filmes e 0 momento político. 


\section{Brasil em tempo de cinema como referência para a crítica engajada}

Se até aqui trilhamos os caminhos metodológicos desenvolvidos em Brasil em tempo de cinema, resta aprofundar o quanto alguns conceitos da obra tornaram-se uma referência para 0 exercício da crítica de cinema engajada. Afinal, o livro permanecia como critério para o jornal alternativo Opinião (1972-1977), onde Bernardet aprofundava sua metodologia. Além disso, quando o crítico entrevistava diretores como Nelson Pereira dos Santos, Oswaldo Caldeira, Joaquim Pedro de Andrade e Pedro Rovai, é possível observar como cineastas de diferentes concepções estéticas procuravam adaptar suas respostas às indagações de Brasil em tempo de cinema sobre a cultura popular e a função do cineasta na sociedade (ADAMATTI, 2015) ${ }^{6}$. Bernardet teve um papel pioneiro no desenvolvimento desses conceitos para a área de cinema, mas ao mesmo tempo o debate estava sintonizado com as exigências dos anos 1970, em um momento de crescente fragmentação da cultura do nacionalpopular. Nesse sentido, os termos da discussão derivam de Bernardet. Porém, evoluem também na correlação com a cultura política daquele momento. Se algumas afirmações de Brasil em tempo de cinema ainda preenchiam o universo discursivo de alguns cineastas dos anos 1970, interessa-nos detalhar, por fim, uma continuidade metodológica do livro com o conceito de ornamento e de estrutura.

Tomamos como exemplo os comentários de Bernardet sobre Walter Hugo Khouri no livro e no jornal Opinião. Não se trata de procurar por uma paternidade da crítica de cinema, mas de traçar uma cadeia evolutiva de critérios de análise fílmica. Em Brasil em tempo de cinema, o cineasta ganhou um adjetivo que não desatrelou dele na década seguinte: a (pretensa) "metafísica de Khouri". A terminologia aponta provavelmente para a expressão "metafísica de Hitchcock", forjada por François Truffaut e Claude Chabrol (Baecque, 2010). Em busca do caráter autoral de Hitchcock, Chabrol teria aprimorado a expressão "larger than life" por metafísica. A reapropriação de conceitos chegava ao cineasta brasileiro não como prova da grandeza do estilo, mas com a pecha de um vazio de sentido.

No livro, a condenação a Khouri passava discretamente por um critério político. Comentando A ilha (1962) e Noite vazia (1964), Bernardet observava duas categorias de personagens. Enquanto os primeiros eram isolados, pervertidos e corruptos, os outros poderiam encontrar uma salvação por serem puros e sensíveis. Nos dois casos, haveria uma tendência ao alheamento diante da vida, em um princípio metafísico. Longe das desordens (provavelmente 
políticas) do mundo, os dois tipos preferem colocar-se a sonhar em atitude angustiada ou romântica. Assim, tanto Khouri quanto Nelson Rodrigues conseguem demonstrar ao público que a riqueza da burguesia decadente não compensa do ponto de vista moral.

Dez anos depois, no jornal Opinião, 0 adjetivo ganhou novas significações nas mãos de Sérgio Augusto. Alargou-se do "princípio metafísico" do livro de 1967 para as "soturnas convulsões metafísicas", porque Khouri conseguia "canalizar energias" em uma "repressora curtição da psicopatologia sexual da plateia" (Augusto; Bernardet, 1975). Em Opinião, Khouri é uma espécie de grande bode expiatório do cinema brasileiro e 0 termo metafisica adquiria o sentido de ausência de preocupação política. Com esse viés, Bernardet (1974) designa $O$ anjo da noite (1974) como um puro exercício de estilo que demoniza o negro. Autoral e didático em seu esquematismo, 0 resultado seria um objeto para enfeitar residências iguais às do filme. Pelas mãos de Gustavo Dahl (1975), veio o sentido mais político. Khouri, com seu cosmopolitismo, tranquilizaria as esferas oficiais, enquanto 0 cuidado plástico forneceria a sensação de ver um bom cinema.

0 parâmetro aplicado a Walter Hugo Khouri em Brasil em tempo de cinema manteve-se em Opinião não só nos críticos engajados, mas também em um raio de influência maior. A partir do critério do ornamento, Marcos Ribas de Faria
(1976) vê $O$ casamento (1975), de Arnaldo Jabor, como uma coluna social, enquanto José Carlos Avellar (1976) tratou Ovelha negra (1974), de Haroldo Marinho Barbosa, como um filme frio, bem acabado e distante de nós mesmos. 0s exemplos multiplicam-se nas páginas do jornal a variados cineastas, tornando-se um valor muito presente. Nesse sentido, entre Brasil em tempo de cinema e Opinião há mais similitudes do que diferenças.

No livro, não só Khouri, mas também David Neves e Júlio Bressane ganharam a pecha de ornamentais. Bernardet condenou a postura contemplativa e nostálgica da câmera de Em busca do ouro (1965), de Gustavo Dahl, por passear imperturbável e elegante por objetos. A preocupação do cineasta seria realizar uma obra de arte requintada e de bom gosto, fugindo do tema político da Inconfidência Mineira. Bernardet insere essa produção no mercado de luxo que vê a arte como objeto decorativo. Sua função é uma forma de preencher 0 vazio da classe média, para que o espectador diga: "realmente, é muito bem feito!" (Bernardet, 2007: p. 26). Sutilmente, o critério é político; para 0 autor, palavras como qualidade $\mathrm{e}$ quantidade "revelam uma fuga da realidade e com as quais a classe média mascara seus problemas" (Bernardet, 2007: p. 26).

Se Opinião prefere utilizar o termo ornamento, a definição do jornal é a de um "invólucro" de qualidade para atingir um público sofisticado. A terminologia empregada indica a presença difusa da política cultural marxista e de uma condenação ao formalismo. Contrária à primazia da forma, a 
crítica marxista opõe-se às propriedades técnicas que reduzem a arte a um jogo estético, além de rejeitar o conteúdo sem política e o mero exercício experimental (Rubim, 1987). A atenção ao viés técnico é vista como uma maneira de tirar a importância histórica da arte. Com um ponto de vista parecido, Brasil em tempo de cinema rejeita a forma e centra seus comentários no conteúdo.

Na adaptação ao cinema brasileiro, desaprovase 0 formalismo por tentar excluir a miséria e as ambiguidades da representação e por trazer uma visão de mundo do Brasil como progresso ou país sem problemas sociais. Cineastas como Walter Hugo Khouri são vistos como burgueses por seu desinteresse em alterar a estrutura da realidade brasileira. A própria terminologia é uma oposição à postura contemplativa e apolítica. Trata-se de uma defesa da arte engajada e um ataque ao núcleo da arte pura. Por detrás destes comentários, os críticos queriam revelar ao público que a forma é ideológica e quer propagar uma imagem positiva do país, benéfica a dois sujeitos em especial, o regime militar e a indústria. Portanto, um filme brasileiro autoral de linguagem acessível, mas sem postura engajada é desaprovado em Brasil em tempo de cinema e em Opinião. Afinal, estava em pauta a fuga de sentido político. Também por causa do contexto ditatorial, um critério externo ao específico do cinema tornava-se um parâmetro analítico muito forte, calcado na ideia de gerar a emancipação crítica do público. Assim, o formalismo enquanto princípio de estudo reunia críticos engajados e os atentos à forma cinematográfica, em um momento no qual a cultura do nacional-popular ainda era central.

\section{A estrutura revisitada}

Se 0 conceito de ornamento mantinha-se em continuidade desde a publicação de Brasil em tempo de cinema até o jornal Opinião, não se pode dizer o mesmo sobre a noção de estrutura. Dez anos depois da publicação de Brasil em tempo de cinema, a forma de trabalho de Jean-Claude Bernardet havia mudado bastante, especialmente ao vincular a análise filmica ao complexo distribuição-exibição. Trata-se de um amplo esforço para deixar de relacionar a classe social e a produção cultural, considerando o tema datado.

Em relação a Lucien Goldman, Opinião não tem tempo nem espaço suficiente para levar a cabo sua metodologia de trabalho. Mesmo assim, cada vez que o jornal retoma a sociologia das visões de mundo, está dialogando com os conceitos goldmanianos aplicados por Jean-Claude Bernardet do livro de 1967. Se o estudo feito no semanário é fragmentado, de qualquer forma tanto a sociologia das visões de mundo quanto Brasil em tempo de cinema são grandes ferramentas para avaliar a produção brasileira. A diferença é que Goldman aplica seu método às grandes obras e sistemas filosóficos, a partir da homologia das estruturas. Enquanto isso, Opinião utiliza essa metodologia para filmes que não atingem a coerência máxima por causa da sobrevivência de elementos ideológicos inconscientes nos autores. 
Trata-se de uma perspectiva menos complexa usada para uma produção considerada menor, que tenta reproduzir a realidade social nos moldes do naturalismo. Ao frisar os dados negativos, 0 estudo de Opinião geralmente incide sobre os fatores ideológicos.

Cabe salientar que o conceito de estrutura de Brasil em tempo de cinema tornou-se muito mais complexo na década seguinte. Em Opinião, Bernardet repensa dois tipos de estrutura fílmica. No primeiro, ele analisa as obras de gênero, as quais são vistas como reflexos distorcidos do real e da constituição da sociedade. Para o cinema de gênero, o método utilizado é 0 da análise do discurso dos filmes, via estudo do enredo. Empregam-se igualmente a sociologia das visões de mundo e o conceito de ornamento. Nestes casos, o fator ideológico predomina, os cineastas são tomados como representativos de uma classe social e a comparação é feita entre a estrutura da sociedade e as relações sociais presentes no filme.

0 segundo caso significa um encontro entre parâmetros do engajamento e do cinema autoral. Trata-se dos filmes brasileiros que procuram analisar a sociedade. 0 critério autoral ressurge indiretamente, mas não como algo negativo ou como ornamento. Esse é o caso de alguns cinemanovistas, como Nelson Pereira dos Santos, Joaquim Pedro de Andrade e Leon Hirzsman, que unem as solicitações estéticas e políticas em uma coincidência com a estrutura da sociedade. Não se trata de mera reprodução ou apreensão do real. Pensando em uma reelaboração factível da realidade, esses cineastas conseguiriam trazer a própria dinâmica da contradição estrutural brasileira na forma fílmica. 0 elogio cabe aos realizadores que "abdicariam" de sua visão de mundo para "incorporar" a das classes populares. Desse modo, o filme seria capaz de captar a estrutura complexa da sociedade e a situação social na forma. Por causa disso, a correlação entre cineasta e classe social não era utilizada, porque os diretores reuniriam características autorais e uma preocupação social. Pelo esforço de trazer o ponto de vista popular, a sociologia das visões de mundo não se reveste de um cunho pejorativo.

Nesses casos, o conceito de estrutura confere um tipo de autenticidade atrelado às contradições da sociedade. 0s artigos tentam averiguar se existe uma similitude entre 0 discurso do filme e uma vontade de transformar a realidade brasileira. Muitas vezes, os textos realçam mais 0 quanto a obra diz respeito à sociedade do que decompõem a análise interna. Bernardet procurava por grandes obras, cujo valor estético é determinado na tensão superada entre a extrema unidade e a extrema riqueza, entre a coerência da estrutura e a multiplicidade do universo imaginário. Por exemplo, os elogios a São Bernardo (1972), de Leon Hirzsman, referem-se a esta capacidade de relacionar as estruturas sociais e fílmicas. Em síntese, a forma do filme consegue captar a dinâmica social e a coisificação do homem. Pouco importa neste caso que Hirzsman seja da 
classe média, porque ele optou pelo ponto de vista das classes populares. Assim, abandonase a comparação entre a origem social e a visão de mundo. São esses filmes que respondem às indagações de Brasil em tempo de cinema porque significam 0 encontro entre um cinema com estética apurada, apelo popular e uma postura engajada pelo Brasil.

\section{Referências}

ADAMATTI, Margarida Maria. A crítica cinematográfica no jornal alternativo Opinião: Frentismo, estética e política nos anos setenta. Tese (Doutorado em Meios e Processos Audiovisuais). Escola de Comunicações e Artes, Universidade de São Paulo, 2015.

AVELLAR, José Carlos. Bolero Serrano. Opinião, Rio de Janeiro, nº 180, p. 20, 16 abr. 1976.

AUGUST0, Sérgio; Bernardet, Jean-Claude. A guerra conjugal de Joaquim Pedro - entrevista concedida a Sérgio Augusto e Jean-Claude Bernardet. Opinião, Rio de Janeiro, nº 127, p. 20, 11 abr. 1975.

BARTHES, Roland. Mitologias. Rio de Janeiro: Difel, 2003.

BAECQUE, Antoine de. Cinefilia - invenção de um olhar, história de uma cultura 1944-1968. São Paulo: Cosac Naify, 2010.

BERNARDET, Jean-Claude. Brasil em tempo de cinema. São Paulo: Cia das Letras, 2007.

. 0 anjo de enfeite. Opinião, Rio de Janeiro, n. 112, p. 21-2, 27 dez. 1974.

DAHL, Gustavo. Coisas de festival... e de filme de índio. Opinião, Rio de Janeiro, nº 117, p. 20, 31 jan. 1975.

FARIA, Marcos Ribas de. 0 casamento, fracassado. Opinião, Rio de Janeiro, nº 169, p. 18, 30 jan. 1976.
FREDERIC0, Celso. A sociologia da literatura de Lucien Goldman. Estudos avançados, São Paulo, v. 19, $\mathrm{n}^{0}$ 54, mai./ago. 2005.

GOLDMAN, Lucien. La sociologie de la littérature: situation actuelle et problèmes de méthode. Revue Internationale des Sciences Sociales. v. XIX, n. 4, 1967. LEITE, Sebastião Uchôa. Cultura Popular: Esboço de uma resenha crítica. Revista Civilização Brasileira, Rio de Janeiro, $\mathrm{n}^{0}$ 4, set. 1965.

LÖWY, Michel; NAÏR, Sami. Lucien Goldmann - ou a dialética da totalidade. São Paulo: Boitempo, 2008.

METZ, Christian. A significação no cinema. São Paulo: Perspectiva, 1972.

NAPOLITANO, Marcos. Coração civil: arte, resistência e lutas culturais durante o regime militar brasileiro (1964-1980). Tese de Livre-Docência, Faculdade de Filosofia, Letras e Ciências Humanas, Universidade de São Paulo, 2011.

PEREIRA, Miguel Serpa. 0 Cinema Novo na Revista Civilização Brasileira. Tese (Doutorado em Ciência da Comunicação). Escola de Comunicações e Artes, Universidade de São Paulo, 2001.

RUBIM, Antonio Albino Canelas. Partido comunista, cultura e política cultural. Tese (Doutorado em Sociologia). Faculdade de Filosofia, Letras e Ciências Humanas, Universidade de São Paulo, 1987.

XAVIER, Ismail; MENDES, Adilson (org.). Ismail Xavier/ Encontros. Rio de Janeiro: Beco do Azougue, 2009. 


\section{Expediente}

A revista E-Compós é a publicação científica em formato eletrônico da Associação Nacional dos Programas de Pós-Graduação em Comunicação (Compós). Lançada em 2004, tem como principal finalidade difundir a produção acadêmica de pesquisadores da área de Comunicação, inseridos em instituições do Brasil e do exterior.

\section{E-COMPÓS I www.e-compos.org.br I E-ISSN 1808-2599}

Revista da Associação Nacional dos Programas de Pós-Graduação em Comunicação.

Brasília, v.19, n.3, set./dez. 2016.

A identificação das edições, a partir de 2008, passa a ser volume anual com três números.

Indexada por Latindex I www.latindex.unam.mx

\section{CONSELHO EDITORIAL}

Alexandre Farbiarz, Universidade Federal Fluminense, Brasil Alexandre Rocha da Silva, Universidade Federal do Rio Grande do Sul, Brasil Ana Carolina Escosteguy, Pontifícia Universidade Católica do Rio Grande do Sul, Brasil Ana Carolina Rocha Pessôa Temer, Universidade Federal de Goiás, Brasil Ana Regina Barros Rego Leal, Universidade Federal do Piauí, Brasil Andrea França, Pontifícia Universidade Católica do Rio de Janeiro, Brasil André Luiz Martins Lemos, Universidade Federal da Bahia, Brasil Antonio Carlos Hohlfeldt, Pontifícia Universidade Católica do Rio Grande do Sul, Brasil Arthur Ituassu, Pontifícia Universidade Católica do Rio de Janeiro, Brasil Álvaro Larangeira, Universidade Tuiuti do Paraná, Brasil Ângela Freire Prysthon, Universidade Federal de Pernambuco, Brasil César Geraldo Guimarães, Universidade Federal de Minas Gerais, Brasil Cláudio Novaes Pinto Coelho, Faculdade Cásper Líbero, Brasil Daisi Irmgard Vogel, Universidade Federal de Santa Catarina, Brasil Denize Correa Araujo, Universidade Tuiuti do Paraná, Brasil

Eduardo Antonio de Jesus, Pontifícia Universidade Católica de Minas Gerais, Brasil Daniela Zanetti, Universidade Federal do Espirito Santo, Brasil

Eduardo Vicente, Universidade de São Paulo, Brasil

Elizabeth Moraes Gonçalves, Universidade Metodista de São Paulo, Brasil Erick Felinto de Oliveira, Universidade do Estado do Rio de Janeiro, Brasil Francisco Elinaldo Teixeira, Universidade Estadual de Campinas, Brasil Francisco Paulo Jamil Almeida Marques, Universidade Federal do Paraná, Brasil Gabriela Reinaldo, Universidade Federal do Ceará, Brasil

Goiamérico Felício Carneiro Santos, Universidade Federal de Goiás, Brasil Gustavo Daudt Fischer, Universidade do Vale do Rio dos Sinos, Brasil Herom Vargas, Universidade Municipal de São Caetano do Sul, Brasil Itania Maria Mota Gomes, Universidade Federal da Bahia, Brasil Janice Caiafa, Universidade Federal do Rio de Janeiro, Brasil Jiani Adriana Bonin, Universidade do Vale do Rio dos Sinos, Brasil
José Afonso da Silva Junior, Universidade Federal de Pernambuco, Brasil José Luiz Aidar Prado, Pontifícia Universidade Católica de São Paulo, Brasil Juçara Gorski Brittes, Universidade Federal de Ouro Preto, Brasil Kati Caetano, Universidade Tuiuti do Paraná, Brasil Lilian Cristina Monteiro França, Universidade Federal de Sergipe, Brasil Liziane Soares Guazina, Universidade de Brasilia, Brasil Luíza Mônica Assis da Silva, Universidade de Caxias do Sul, Brasil Luciana Miranda Costa, Universidade Federal do Pará, Brasil Malena Segura Contrera, Universidade Paulista, Brasil Monica Martinez, Universidade de Sorocaba, Brasi Maria Ataide Malcher, Universidade Federal do Pará, Brasil Marcia Tondato, Escola Superior de Propaganda e Marketing, Brasil Marcel Vieira Barreto Silva, Universidade Federal da Paraíba, Brasil Maria Clotilde Perez Rodrigues, Universidade de São Paulo, Brasil Maria das Graças Pinto Coelho, Universidade Federal do Rio Grande do Norte, Brasil Mauricio Ribeiro da Silva, Universidade Paulista, Brasil

Mauro de Souza Ventura, Universidade Estadual Paulista, Brasil Márcio Souza Gonçalves, Universidade do Estado do Rio de Janeiro, Brasil Micael Maiolino Herschmann, Universidade Federal do Rio de Janeiro, Brasil Mirna Feitoza Pereira, Universidade Federal do Amazonas, Brasil Nísia Martins Rosario, Universidade Federal do Rio Grande do Sul, Brasil Potiguara Mendes Silveira Jr, Universidade Federal de Juiz de Fora, Brasil Regiane Regina Ribeiro, Universidade Federal do Paraná, Brasil Rogério Ferraraz, Universidade Anhembi Morumbi, Brasil Rose Melo Rocha, Escola Superior de Propaganda e Marketing, Brasil Rozinaldo Antonio Miani, Universidade Estadual de Londrina, Brasil Sérgio Luiz Gadini, Universidade Estadual de Ponta Grossa, Brasil Simone Maria Andrade Pereira de Sá, Universidade Federal Fluminense, Brasil Veneza Mayora Ronsini, Universidade Federal de Santa Maria, Brasil Walmir Albuquerque Barbosa, Universidade Federal do Amazonas, Brasil

\section{CONSELHO CIENTÍFICO}

Cristiane Freitas Guttreind, Pontifícia Universidade Católica do Rio Grande do Sul, Brasil Eduardo Morettin, Universidade de São Paulo, Brasil Felipe Costa Trotta, Universidade Federal Fluminense, Brasil Irene de Araújo Machado, Universidade de São Paulo, Brasil

\section{COMISSÃO EDITORIAL}

Eduardo Antonio de Jesus, Pontifícia Universidade Católica de Minas Gerais, Brasil Osmar Gonçalves dos Reis Filho, Universidade Federal do Ceará, Brasil

\section{CONSULTORES AD HOC}

Geane C. Alzamora, Universidade Federal de Minas Gerais, Brasil Teresinha Cruz Pires, Pontifícia Universidade Católica de Minas Gerais, Brasil

\section{EQUIPE TÉCNICA}

ASSISTENTE EDITORIAL Márcio Zanetti Negrini

REVISÃO DE TEXTOS Press Revisão

EDITORAÇÃO ELETRÔNICA Roka Estúdio

IMAGEM DE CAPA Silas de Paula

\section{COMPÓS I www.compos.org.br}

Associação Nacional dos Programas de Pós-Graduação em Comunicação

Presidente

Edson Fernando Dalmonte

Programa de Pós-Graduação em Comunicação

e Cultura Contemporânea - UFBA

edsondalmonte@uol.com.br

Vice-presidente

Cristiane Freitas Gutfreind

Programa de Pós-Graduação em Comunicação Social - PUC-RS cristianefreitas@pucrs.br

Secretário-Geral

Rogério Ferraraz

Programa de Pós-Graduação em Comunicação

Universidade Anhembi Morumbi

rogerioferraraz@anhembimorumbi.edu.br

CONTATO I revistaecompos@gmail.com 